\title{
Effects of the perceptions of online quizzes and electronic devices on student performance
}

Fabrizio Di Meo

Universidad de Alcalá, Spain

\section{Carmen-Pilar Martí-Ballester}

Universitat Autònoma de Barcelona, Spain

\begin{abstract}
This study assessed how students' perceptions of online quizzes and the use of three electronic devices to solve them affected their performance. A sample of 208 students enrolled in an introductory accounting course at the Universitat Autònoma de Barcelona completed online quizzes as part of their evaluation and filled in a questionnaire on their perceptions of such quizzes and the electronic devices they used to do them on. Their scores were collected both for the online quizzes and their examinations, and the data were then analysed using a partial least square structural equation model. Findings suggest that a positive perception of online quizzes positively affected students' examination scores, but not their scores for the online quizzes. The findings also indicate that, while positive perceptions of computers and tablet PCs for doing online quizzes did not affect students' examination scores, those who reported positive perceptions of the use of mobile phones for online quizzes obtained significantly lower examination scores than their peers. Finally, perception of the use of any electronic device did not affect students' scores for online quizzes. Implications for instructors, faculty administrators, and students are provided based on the results.
\end{abstract}

Implications for practice or policy:

- Students should be aware of the benefits of using online quizzes to test their knowledge, rather than to learn course content.

- Instructors should clearly explain the purpose of self-assessment to students.

- Instructors should integrate learning activities with complementary learning resources for mobile phones.

Keywords: online quizzes, mobile phones, self-assessment, survey, PLS-SEM approach.

\section{Introduction}

Continuous assessment, which is characterised by providing feedback to students (Buchanan, 2000), represents a way not only to assess students' knowledge but also to increase their motivation and commitment to learn (William \& Black, 1996). An efficient way to conduct continuous assessment is using online multiple-choice questions (also called quizzes), as they are relatively easy to implement (Martí Ballester \& Orgaz Guerrero, 2014). Students can use different electronic devices, such as computers, tablet PCs or mobile phones, to answer these questions. The importance of electronic devices in the learning process has increased, as they have become common in our everyday lives (Alvarez, Brown, \& Nussbaum, 2011).

Although previous literature has analysed how computers (Bonham, Deardorff, \& Beichner, 2003; Miller, 2009; Ozok, Benson, Chakraborty, \& Norcio, 2008; Ricketts \& Wilks, 2002), tablets (Alvarez et al., 2011; Enriquez, 2010; Ferrer, Belvís, \& Pàmies, 2011; Li, Pow, Wong, \& Fung, 2010), and mobile phones (Boticki, Baksa, Seow, \& Looi, 2015; Hwang \& Chang, 2011; Hwang, Yang, Tsai, \& Yang, 2009; Nikou \& Economides, 2016; Shih, Chu, Hwang, \& Kinshuk, 2011; Song, 2014) can separately affect students’ learning process, little research has been dedicated to analysing how students' perceptions of the use of online quizzes for continuous assessment, and of the use of computers, tablet PCs, and mobile phones to do online quizzes can influence performance, that is, students' course grades (Summers, Waigandt, \& Whittaker, 2005). Also, although previous literature has focused mainly on the use of specific electronic devices for continuous assessment, little is known about what happens when students can choose which electronic devices to use for online quizzes. Finally, the effect of students' perceptions of the use of 
computers, tablets, and mobile phones for online quizzes on their perception of the use of online quizzes for continuous assessment has not been widely explored.

This research contributes to the existing literature in several ways. First, it extends on the findings of previous research related to online multiple-choice questions for assessing students' knowledge. Although previous literature has found that online quizzes are more efficient and more satisfactory for students than paper-and-pencil quizzes (Marriott \& Lau, 2008; Segall, Doolen, \& Porter, 2005), this conclusion may depend on the structure of the tests. In this study, students could repeat the quizzes without penalisation, which might have led some students to take the tests to study the content of a course, rather than to selfevaluate their knowledge. This different use of online quizzes might affect students' performance (scores) in these quizzes and/or in paper-and-pencil examinations compared with online quizzes. Second, this study investigated the effect of students' perceptions of the use of electronic devices on performance by allowing them to take the tests using computers, tablets, and/or mobile phones, thus avoiding misspecification problems if only one electronic device was considered. Finally, this study attempted to fill the gap regarding the associations between students' perceptions of the use of electronic devices to do online quizzes and their perception of quizzes for continuous assessment.

To this end, online quizzes on the Moodle platform were implemented for each topic of the Introduction to Accounting course at the Universitat Autònoma de Barcelona during the second term of the 2015-2016 academic year. In addition, students' perceptions of online quizzes for continuous assessment, and of electronic devices to do online quizzes, were obtained through a survey distributed at the end of the course. This study used the explanatory factor analysis and partial least square approach in two steps to analyse the data.

\section{Hypotheses development}

To obtain the constructs regarding students' perceptions of the use of the three electronic devices (computers, tablet PCs, and mobile phones) to do online quizzes, this study used a version of the activity theory that was adapted to analyse the use of such electronic devices as mobile phones for educational purposes (Liaw, Hatala, \& Huang, 2010). According to activity theory, learning is defined as a cultural and historical activity system, which is mediated by tools that are able to constrain or support learners in producing their knowledge and developing their skills. Engeström (1999) provided a framework in which tools mediated learning activities that were based on rules, community, and division of labour. These three components were later renamed control, context, and communication (Sharples, Taylor, \& Vavoula, 2005), on the basis of which Liaw et al. (2010) defined four factors related to learning activities using electronic devices, arguing in particular that control of learning could refer to (1) students' autonomy with a technology; the context of learning could be viewed as (2) students' function (user-friendliness) and (3) satisfaction with a technology; and the communication of learning could be viewed as (4) activities that could be completed using electronic devices for learning purposes. We expected autonomy, function, satisfaction, and activities to have an influence on technology acceptance. Thus, to obtain the constructs for each electronic device, the items autonomy, function, satisfaction, activities, and acceptance, as defined in Liaw et al. (2010), were used.

Next, the hypotheses related to online quizzes, electronic devices, and students' performance in online quizzes and examinations were formulated.

\section{Online multiple-choice questions and student performance}

In recent decades, online multiple-choice questions have been increasingly used in higher education to assess students' knowledge. Several factors, such as the growing number of students, decreasing resources in the universities of several countries, and increased usage of computers, tablet PCs, and mobile phones, have motivated the increasing use of online quizzes as learning resources (Nicol, 2007).

Students seem to appreciate quizzes with minimal feedback because, through them, they are able to verify their own knowledge of a particular subject (Bälter, Enström, \& Klingenberg, 2013). Students' satisfaction further increases with online multiple-choice questions, compared to paper-and-pencil quizzes, as they need less time to answer online questions (Segall et al., 2005). Online quizzes also provide immediate feedback to students, while the feedback from paper-and-pencil quizzes takes longer to reach them. After taking 
online quizzes, students are able to immediately compare their actual knowledge with the knowledge they thought they had (Bälter et al., 2013). As a result, students are encouraged to study continuously over a term (Marriott \& Lau, 2008). The efficiency of online multiple-choice questions is likely to further increase if academic staff allow students to repeat the quizzes. In fact, the repeating of quizzes until a satisfactory score has been achieved increases students' motivation and provides the opportunity for them to revise specific topics to catch up (Nicol, 2007).

Although some literature claims that online quizzes are ineffective, as they do not have a significant positive effect on students' examination performance (Segall et al., 2005), especially if quizzes are used to learn course content rather than to test knowledge (Brothen \& Wambach, 2001), this study formulated the related hypotheses following the stream of literature supporting a positive association between online quizzes and student performance (Martí Ballester \& Orgaz Guerrero, 2014). In particular, this study used students' perception of online quizzes, that is, critical assessment of their quality and utility as learning activities, following Duffy and Jonassen (1992) and MacDonald and Gabriel (1998). By allowing students to repeat the quizzes within a limited period of time until achieving a satisfactory score that meets their own expectations, it was hypothesised that students reporting a positive perception of their learning experience with online quizzes would score better in both online quizzes and in paper-and-pencil exams. Because the scores for online quizzes were also likely to have an impact on students' examination scores, a positive association between the two types of performance was also expected. This led to the first three hypotheses:

H1: Positive perceptions of online quizzes increase students' scores for online quizzes.

H2: Positive perceptions of online quizzes increase students' examination scores.

H3: Higher scores for online quizzes increase students' examination scores.

\section{Computers for online multiple-choice questions and student performance}

Computers were the first electronic devices to be considered in previous literature on the effects of online multiple-choice questions on student performance and satisfaction. Compared to other electronic devices, such as tablets and mobile phones, computers have several advantages. In reading tasks, they are likely to be more comfortable than other electronic devices, as their screens are normally relatively bigger than those of tablets or mobile phones (Ozok et al., 2008). Also, in both typing and form-filling tasks, users are likely to be more satisfied when using computers than other electronic devices, as computers make such tasks easier through such features as a touch pad, eraser head pointer, trackball, or external mouse (Ozok et al., 2008). In addition, recent technological advances regarding screen size, hard disk storage, processor speed, and wireless communication technologies have further increased user satisfaction. Improvements in computer portability have also been achieved through the increasing popularity and sales of laptops rather than desktops (Elliott-Dorans, 2018).

With regard to the effects that computer-based assessment are likely to have on student performance, several studies (Gretes \& Green, 2000; Lowther, Ross, \& Morrison, 2003; Wilson, Boyd, Chen, \& Jamal, 2011) have found that students perform significantly better after computers are introduced as a tool for learning and assessment. However, other researchers have observed that student performance improved only moderately (Miller, 2009) or even that the use of computers for assessment implies no improvement in student performance (Bonham et al., 2003; Ricketts \& Wilks, 2002).

This study evaluated students' knowledge through both paper-and-pencil examinations and frequent online quizzes. The latter included the chance to repeat quizzes in order to increase familiarity with computerbased evaluation (Ricketts \& Wilks, 2002). The association between the perception of the use of computers to do online quizzes and student performance was also analysed with respect to paper-and-pencil quizzes and practical exams (examination scores). Finally, the association between students' perception of the use of computers to do online quizzes and their perception of online quizzes was also considered, with the students with more favourable perceptions of the use of computers being expected to report better perceptions of online quizzes. Thus, the corresponding hypotheses were formulated as follows:

H4: Positive perceptions of the use of computers for online quizzes increase students' scores for online quizzes.

H5: Positive perceptions of the use of computers for online quizzes increase students' examination scores. 
H6: Positive perceptions of the use of computers for online quizzes improve students' perceptions of online quizzes.

\section{Tablet PCs for online multiple-choice questions and student performance}

Because computers limit mobility and interaction with other students (Ozok et al., 2008), other electronic devices, such as tablet PCs, could be used. Tablets stimulate interactions between students and involve members in group discussions better than computers (Wardley \& Mang, 2016) because they are easy to carry (Alvarez et al., 2011), especially in problem-solving intensive courses (Enriquez, 2010).

Previous literature has found that the use of tablets has a positive impact on student performance (Enriquez, 2010; Huang \& Lin, 2017) and that students expect the use of tablets to perform tasks to improve their learning processes (Ifenthaler \& Schweinbenz, 2016). However, these positive effects are likely to depend on students' socio-economic and cultural background (Ferrer et al., 2011), as well as their technological literacy and learning style, especially in underdeveloped areas (Pruet, Ang, \& Farzin, 2016). Also, Heflin, Shewmaker, and Nguyen (2017) observed that students using tablets for learning activities reported lower engagement during the learning process, and less critical thinking, while Scibora, Mead, and Larson (2018) found that students using tablets did not achieve better academic performance than their peers.

To investigate further, this study also analysed the impact of the perception of the use of tablets for learning activities on student performance by differentiating between scores for online quizzes and examinations. Hypotheses 7 and 8 were formulated by taking into account the increase in interactions between students due to the use of tablets for learning activities, while hypothesis 9 suggests a positive association between perceptions of the use of tablets to do online quizzes and students' perceptions of online quizzes.

H7: Positive perceptions of the use of tablets for online quizzes increase students' scores for online quizzes.

H8: Positive perceptions of the use of tablets for online quizzes increase students' examination scores.

H9: Positive perceptions of the use of tablets for online quizzes improve students' perceptions of online quizzes.

\section{Mobile phones for online multiple-choice questions and student performance}

The tremendous growth in the use of mobile phones and the advances in wireless communication technologies has led researchers to analyse whether they can be efficiently used as a way for students to learn. Mobile phones can be particularly attractive because students are situated in real-world scenarios with access to online resources related to academic courses (Hwang \& Chang, 2011). This suggests that students have the possibility to learn any time and anywhere (Liaw et al., 2010). The small size of mobile phones and the fact that they can be carried easily also enable students to access the Internet from anywhere. This is a huge advantage, especially for students who are engaged in activities other than their learning tasks, such as those attending university who are also working or have family duties.

A number of studies in the literature have stated that mobile phones are likely to improve students' knowledge of content (de-Marcos et al., 2010; Hwang \& Chang, 2011; Looi, Sun, \& Xie, 2015; Song, 2014) and their perception of their learning achievements (Nikou \& Economides, 2016). Also, the quantity and quality of primary schoolchildren's interactions and comments on specific platforms designed for mobile phones were able to predict final grades (Boticki et al., 2015). However, some previous studies found that, although students enjoyed the experience of using mobile phones for learning activities, there were small or non-significant negative effects on performance between the use of mobile phones and other electronic devices (Garcia-Cabot, de-Marcos, \& Garcia-Lopez, 2015; Kates, Wu, \& Coryn, 2018; Romero, Ventura, \& de Bra, 2009), and that students using mobile phones while performing learning activities were less engaged and demonstrated less critical thinking (Q. Chen \& Yan, 2016; Heflin et al., 2017; Junco \& Cotten, 2012).

This study analysed the effect of the perception of the use of mobile phones for learning activities not only on scores for online quizzes but also examination scores, which has implications for the use of mobile phones to study course content. Mobile phones normally have smaller screens than computers and tablets, 
making reading, typing, form-filling, and studying course content in general less comfortable with respect to other electronic devices. These characteristics of mobile phones, which are likely to affect learning processes, may have a negative effect on students' performance. Thus, students using mobile phones for learning activities were not expected to perform as well as their peers using other electronic devices. However, the use of mobile phones to do online quizzes was likely to be particularly useful for those students who had little time to spend on studying course content due to, for example, work, family, and social commitments, which led us to formulate a positive association between perceptions of the use of mobile phones for online quizzes and students' perception of online quizzes.

H10: Positive perceptions of the use of mobile phones for online quizzes decrease students' scores for online quizzes.

H11: Positive perceptions of the use of mobile phones for online quizzes decrease students' examination scores.

H12: Positive perceptions of the use of mobile phones for online quizzes improve students' perceptions of online quizzes.

Figure 1 illustrates the proposed model.

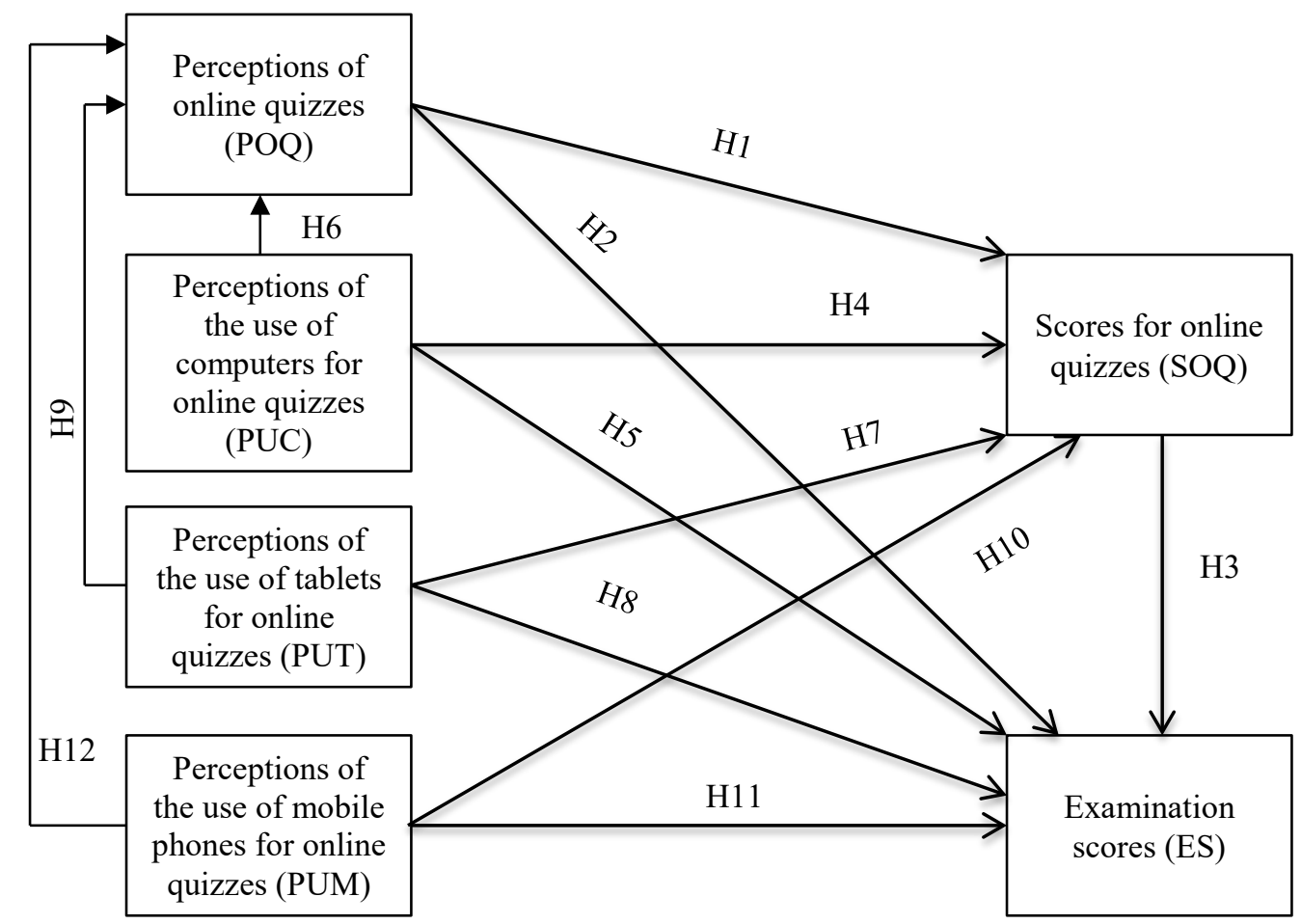

Figure 1. Initial conceptual model

\section{Research method}

\section{Data collection and participants}

To test the formulated hypotheses, a survey (Di Meo \& Martí Ballester, 2019) was distributed to undergraduate economics and business students at the Universitat Autònoma de Barcelona at the end of the second term, in June 2016. Participation in the survey was voluntary and not anonymous, although responses were kept confidential. A total of 261 students were enrolled for the Introduction to Accounting course. Around 18\% (46) of those dropped out, while approximately $82 \%$ (215) completed and returned the survey, which was delivered to them right before the final examination. In total, 208 valid responses were obtained (response rate: 96.74\%). The sample size is small but sufficient to provide efficient and robust results according to Terzis and Economides (2011), given that the sample size is greater than the minimum number of 100 observations, ten times the maximum number of items for the most complex 
construct, and five times the number of estimated parameters impacting a dependent variable. Table 1 reports the descriptive statistics of the sample.

Table 1

Demographic profile of respondents

\begin{tabular}{llcc}
\hline & Demographic profile & Frequency & Percentage \\
\hline \multirow{2}{*}{ Gender } & Male & 131 & 62.98 \\
& Female & 77 & 37.02 \\
\hline Age & $18-19$ & 104 & 50.00 \\
& $20-24$ & 93 & 44.71 \\
& $25-39$ & 11 & 5.29 \\
\hline Final academic grade & $0.00-4.99$ & 68 & 32.69 \\
& $5.00-6.99$ & 86 & 41.35 \\
& $7.00-8.99$ & 47 & 22.60 \\
& $9.00-10.00$ & 7 & 3.36 \\
\hline Average quiz score & $0.00-4.99$ & 30 & 14.42 \\
& $5.00-6.99$ & 37 & 17.79 \\
& $7.00-8.99$ & 79 & 37.98 \\
& $9.00-10.00$ & 62 & 29.81 \\
\hline Faculty & Business & 68 & 32.69 \\
& Economics & 140 & 67.31 \\
\hline Devices used & None & 1 & 0.48 \\
& Only mobile & 5 & 2.40 \\
& Only tablet & 9 & 4.33 \\
& Only computer & 108 & 51.92 \\
Invalid responses & Mobile and tablet & 1 & 0.48 \\
& Mobile and computer & 40 & 19.23 \\
& Tablet and computer & 14 & 6.74 \\
& Mobile, tablet, and computer & 30 & 14.42 \\
\hline Students enrolled & & 261 & 100 \\
& & 215 & 82.38 \\
& & 7 & 3.26 \\
\hline
\end{tabular}

\section{Measures}

For this study, survey items were developed based on previous literature (Chen, 2011; Kim \& Jin, 2015; Liaw et al., 2010; Sánchez-Franco, Peral-Peral, \& Villarejo-Ramos, 2014) for measuring the constructs called perceptions of online quizzes (POQ), perceptions of the use of computers for online quizzes (PUC), perceptions of the use of tablets for online quizzes (PUT), and perceptions of the use of mobile phones for online quizzes (PUM). The items to measure the constructs above used a 5-point Likert scale, which ranged from 1 (strongly disagree) to 5 (strongly agree). To obtain the scores for online quizzes (SOQ) construct, the highest scores for each of the six quizzes corresponding to each of the six topics were used. The scores could take a value between 0 and 10, according to the university's rules. The examination scores (ES) were students' grades, also with values between 0 and 10, in the three paper-and-pencil exams (two quizzes and one practical exam).

\section{Data analysis}

The survey data and research models were analysed using the exploratory factor analysis (EFA) and partial least squares (PLS) approach in two steps. First, the reliability and validity of each construct within the measurement model were examined. Next, the hypotheses were tested using the structural model.

EFA was applied to the items of each construct using the normalised varimax rotation method with the SPSS version 19 software package. All the items with a factor loading higher than 0.6 (Tang \& Austin, 2009) represented only one factor with eigenvalue greater than 1 , while items that were poorly loaded were dropped. The adequacy of the factor analysis was measured by adopting Bartlett's test of sphericity and the Kaiser-Meyer-Olkin test. A confirmatory factor analysis using the PLS approach with the SmartPLS 3.0 
statistical software (PLS-SEM) was implemented to examine the reliability and validity of the scales (Ringle, Wende, \& Becker, 2014-2019).

Structural equation modelling (SEM) was used to examine the relationship between the second-order latent constructs (Figure 1) obtained using principal component analysis (J. Chen, 2011) as previously described. These relationships between the second-order latent constructs were estimated using a partial least square structural equation model (PLS-SEM). However, PLS-SEM does not provide a significant test of parameters and does not estimate the confidence intervals. For this reason, a bootstrap resampling method with 200 random subsamples from the original dataset was implemented to obtain the standardised path coefficients and the corresponding statistical significance levels using PLS-SEM.

\section{Results}

\section{Assessment of the measures}

The results of the EFA tests are shown in Figure 2. The Kaiser-Meyer-Olkin tests were greater than 0.6 and Bartlett's test of sphericity was significant with $p$ values lower than 0.05 for all constructs, showing that the factor analysis had an optimal level of adequacy (Barkatsas, Kasimatis, \& Gialamas, 2009).

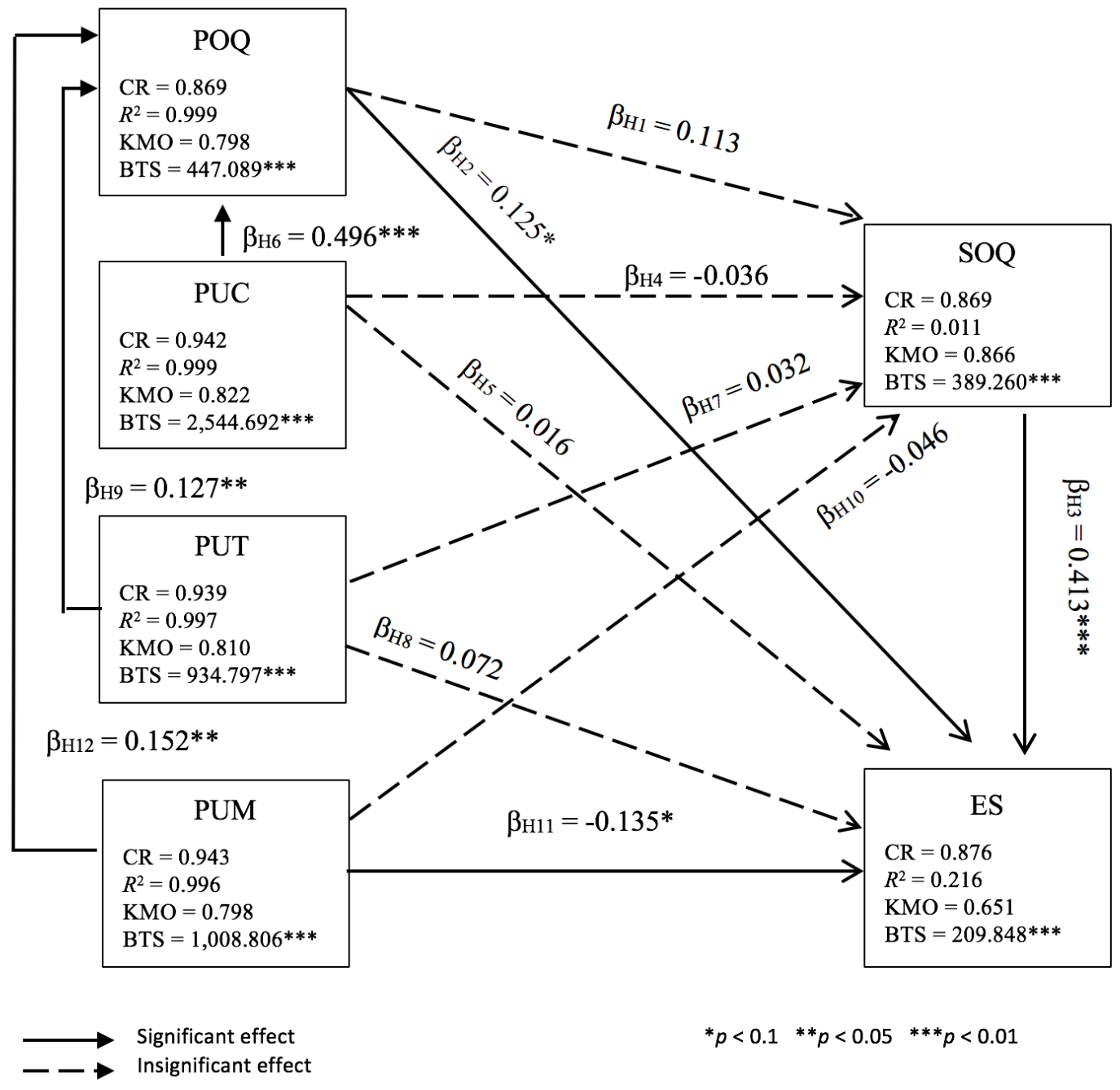

Figure 2. Result of the structural model analysis. CR - composite reliability; KMO - Kaiser-Meyer-Olkin; BTS - Bartlett's test of sphericity 
Taking into account the results obtained from the Kaiser-Meyer-Olkin test and Bartlett's test of sphericity, and from the factor loading of each item, the scales to evaluate the construct $P O Q$ were composed of two dimensions: self-assessment and satisfaction. The scales to evaluate the construct PUC were based on two dimensions: activities, satisfaction and function and acceptance. Similarly, the scales to assess the construct PUT were composed of four dimensions: activities and function, satisfaction, autonomy, and acceptance. Finally, the scales to measure the construct PUM were represented by three dimensions: autonomy and function, activities and satisfaction, and acceptance.

\section{Validity and reliability of the proposed scales}

The results of the factor loadings of each item, the Cronbach's alpha coefficient, and the average variance extracted (AVE) for each construct are shown in Figure 3. After dropping the items with values below the recommended threshold of 0.7 in the corresponding construct, the item loadings ranged from 0.750 to 0.983 and were significant at a level of 5\%. This indicates that the scales applied to each construct were valid (J. Chen, 2011). Furthermore, each Cronbach's alpha coefficient ranged from 0.756 to 0.964 in the first-order and second-order constructs. All these values for Cronbach's alpha coefficients were greater than the threshold of 0.7 (Nunnally \& Bernstein, 1994), ensuring the internal consistency and validity of the firstand second-order constructs (Martí-Ballester \& Simon, 2017). This internal consistency was confirmed by the results obtained in the AVE from each construct, whose values ranged from 0.672 to 0.962 in the firstorder constructs and from 0.527 to 0.703 in the second-order constructs. In both cases, these values exceeded the 0.5 threshold (Fornell \& Larcker, 1981), ensuring a strong convergent validity between the items that measured a construct.

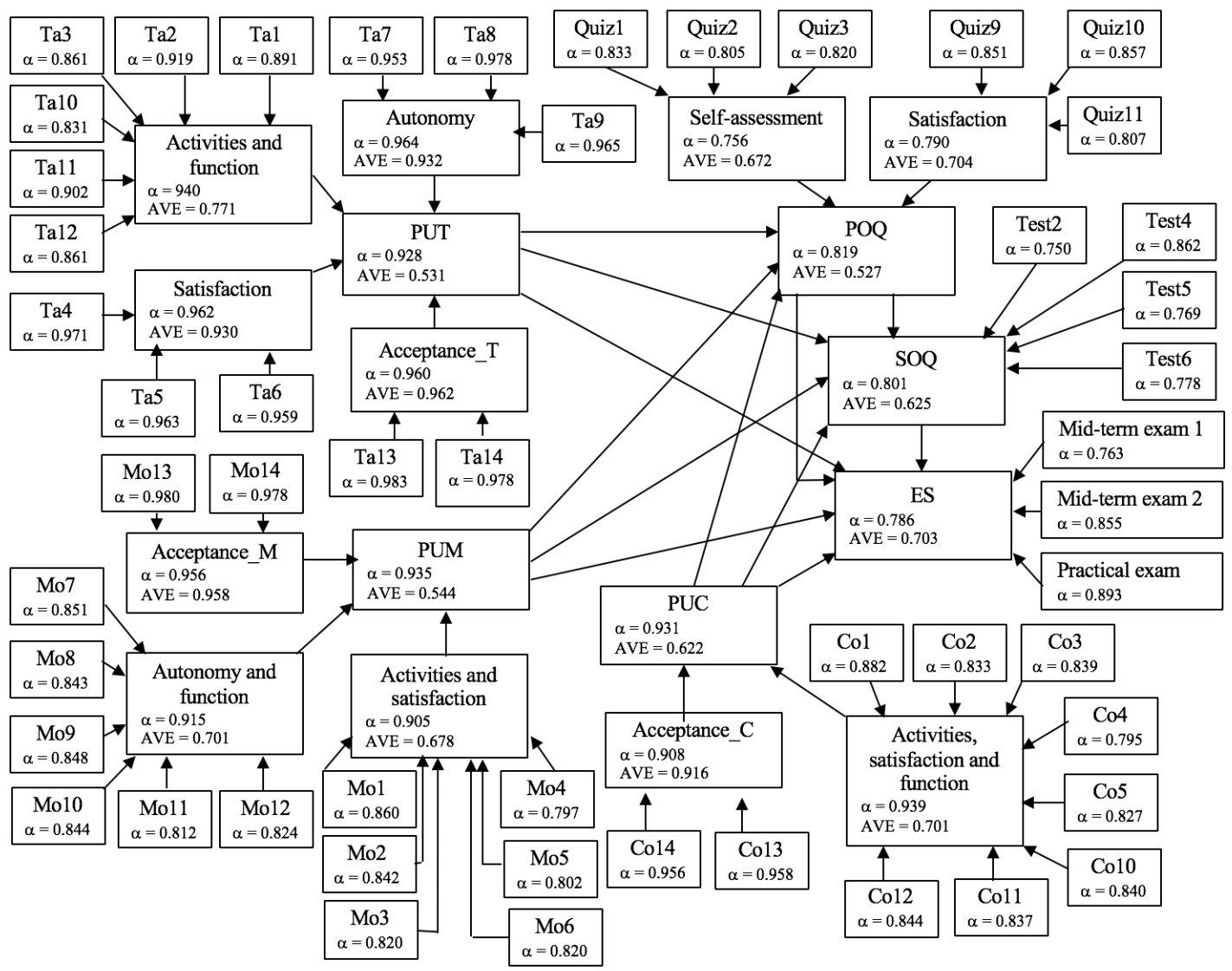

Figure 3. Validity and reliability of the proposed scales

The results for the discriminant validity are shown in Table 2, with the square root of every AVE for each construct being higher than the correlation between the latent constructs of interest. This ensured the unidimensionality of each factor (Fornell \& Larcker, 1981). 
The reliability of each second-order construct was assessed through composite reliability. Figure 2 summarises these results, whose values, from 0.869 to 0.943 , were greater than the recommended threshold of 0.80 (Nunnally, 1978). These findings demonstrate that the variance captured by the factors was significantly higher than the variance indicated by the error components and suggested a satisfactory reliability of all the constructs (Martí-Ballester \& Simon, 2017).

Table 2

Correlation between latent constructs

\begin{tabular}{|c|c|c|c|c|c|c|c|c|c|c|c|}
\hline & 1 & 2 & 3 & 4 & 5 & 6 & 7 & 8 & 9 & 10 & 11 \\
\hline $\begin{array}{l}\text { 1. Activities, } \\
\text { satisfaction and } \\
\text { function_C }\end{array}$ & 0.837 & & & & & & & & & & \\
\hline $\begin{array}{l}\text { 2. Activities and } \\
\text { function_T }\end{array}$ & 0.195 & 0.878 & & & & & & & & & \\
\hline $\begin{array}{l}\text { 3. Autonomy and } \\
\text { function } M\end{array}$ & 0.216 & 0.325 & 0.837 & & & & & & & & \\
\hline 4. Satisfaction_T & 0.131 & 0.651 & 0.197 & 0.964 & & & & & & & \\
\hline $\begin{array}{l}\text { 5. Activities and } \\
\text { satisfaction_M }\end{array}$ & 0.044 & 0.214 & 0.670 & 0.210 & 0.823 & & & & & & \\
\hline 6. Acceptance_C & 0.513 & 0.074 & 0.040 & 0.102 & 0.025 & 0.957 & & & & & \\
\hline 7. Acceptance_M & 0.066 & 0.224 & 0.531 & 0.217 & 0.482 & 0.161 & 0.979 & & & & \\
\hline 8. Autonomy_ $\bar{T}$ & 0.057 & 0.323 & 0.111 & 0.407 & 0.042 & 0.102 & 0.043 & 0.965 & & & \\
\hline 9. Acceptance_T & 0.158 & 0.489 & 0.137 & 0.426 & 0.177 & 0.242 & 0.217 & 0.186 & 0.981 & & \\
\hline $\begin{array}{l}10 \text {. Self- } \\
\text { assessment_Q }\end{array}$ & 0.442 & 0.255 & 0.245 & 0.184 & 0.134 & 0.348 & 0.157 & 0.133 & 0.124 & 0.820 & \\
\hline 11.Satisfaction_Q & 0.475 & 0.240 & 0.236 & 0.120 & 0.170 & 0.347 & 0.213 & 0.137 & 0.097 & 0.533 & 0.839 \\
\hline
\end{tabular}

\section{Conceptual model and hypotheses testing}

A structural model path analysis was used to examine the relationship between the second-order latent constructs (Figure 1) obtained from the principal component analysis (J. Chen, 2011). The results from testing the initial structural equation model are shown in Figure 2; they indicate that all the significant path coefficients were above the absolute value threshold of 0.1 (Sellin \& Keeves, 1994). The constructs $P O Q$ and $S O Q$ had a positive and significant direct effect on the $E S$ construct. The effect of $S O Q$ (path coefficient $=0.413 ; p<0.001$ ) was stronger than the effect of the $P O Q$ (path coefficient $=0.125 ; p=0.065$ ). Both of the first-order constructs integrated in the quizzes latent variable had similar weights of around 0.7 . Thus, hypotheses $\mathrm{H} 3$ and $\mathrm{H} 2$ were supported with significance levels of $1 \%$ and $10 \%$, respectively. These results are consistent with Bälter et al. (2013). However, the effect of $P O Q$ on $S O Q$ was not significant at conventional levels. Therefore, hypothesis H1 was not supported.

The construct $P U C$ positively and directly affected the $P O Q$, according to the path coefficient of 0.496 ( $p$ $<0.001)$. Likewise, the effects of both $P U T$ and $P U M$ on $P O Q$ were positive and significant with path coefficient values of $0.127(p=0.027)$ and $0.152(p=0.039)$, respectively. These findings support hypotheses H6, H9, and H12. On the contrary, the construct PUM negatively and directly affected ES, as indicated by a path coefficient of -0.135 and a significance level of $10 \%(p=0.058)$. Activities and satisfaction and autonomy and function were the most important variables for predicting the mobile latent variable, as they reported weights of 0.541 and 0.500 , respectively. Therefore, hypothesis H11 was supported, a result consistent with the findings of Junco and Cotten (2012). The path coefficient analysing the indirect effect of the PUM on ES through the mediation of the construct $S O Q$ was not significant at conventional levels. Therefore, hypothesis H10 was not supported. The remaining four paths related to the associations between the perceptions of electronic devices and students' performance were not significant at conventional levels and did not support the related hypotheses (H4, H5, H7, and H8). These results indicate that students reporting positive perceptions of tablets obtained similar scores for online quizzes and paper-and-pencil examinations to those reporting positive perceptions of computers.

Thus, significant predictors of ES were $P O Q, S O Q$, and $P U M$, which jointly explained $21.7 \%$ of the variance $\left(R^{2}\right)$. This value, which is higher than the threshold of 0.20 recommended by Hair, Ringle, and Sarstedt (2011), represented the predictive power of the proposed model. Furthermore, the value of the 
goodness of fit of the overall model was 0.838 , which exceeded the cut-off value of 0.36 (Terzis \& Economides, 2011), while the value of the standardised root mean square residual test was 0.093 , which was lower than the value of 0.10 recommended by Henseler (2014) and thus validated the good fit of the proposed structural model. To check robustness, a revised structural equation model avoiding the $S O Q$ construct was produced. The path coefficient values and significance levels were similar to those of the initial structural equation model, the value of the standardised root mean square residual measure being equal to 0.096 .

\section{Discussion of the results}

With regard to the perception of online quizzes, the results reveal that the corresponding construct did not significantly affect scores (hypothesis H1), which is consistent with Brothen and Wambach (2001), meaning that participants who used online quizzes for self-assessment obtained similar scores to participants who used online quizzes to study the course content. Although online quizzes are designed for students to assess their knowledge on their own after studying the content of an accounting topic, the possibility of unlimited attempts at each quiz without penalisation could encourage some students to study the content of each topic using online quizzes. On the contrary, the participants who scored best at online quizzes also obtained significantly better examination scores (hypothesis H3). This positive association was obtained regardless of whether students used online multiple-choice questions to check their knowledge or to study the content of an accounting topic. This finding is consistent with the results on the effect of online quizzes on academic performance reported by Martí Ballester and Orgaz Guerrero (2014), indicating that the use of online quizzes helps to enhance students' examination scores. The result for the positive association between perceptions of online quizzes and examination scores (hypothesis 2) reveals that students who use online quizzes to self-assess their knowledge, rather than to study the course content, possibly developed greater abilities through the use of online quizzes by detecting and revising any comprehension problems or gaps during their learning process. These abilities enabled students to increase their knowledge about the Introduction to Accounting course topics and thus achieve better examination scores, which is consistent with Bälter et al. (2013) and Marriott and Lau (2008).

With regard to electronic devices, the results show that the perception of the use of any electronic device for online quizzes positively affects perceptions of online quizzes (hypotheses H6, H9, and H12), which is consistent with the findings of Bälter et al. (2013) and Segall et al. (2005). The effect of the perceptions of computers was greater than that of the other electronic devices. Thus, the advantages of using computers, as detailed by Ozok et al. (2008), helped to improve students' perception of online quizzes more than the advantages of using tablets or mobile phones, as mentioned by Chang, Yan, and Tseng (2012) and ElliottDorans (2018). Although previous studies did not examine the effect of perceptions of the use of electronic devices for online quizzes on students' scores, the present study reveals that the associations between the perception of the use of any electronic device to do online quizzes and students' scores for online quizzes (hypotheses H4, H7, and H10) were not significant at conventional levels. Students reporting a positive perception of mobile phones to do online quizzes achieved, on average, similar scores for online quizzes to those who reported a positive perception of computers and tablets. This indicates that mobile phones are as effective as other electronic devices for online quizzes, probably due to user interfaces being adapted to each electronic device and students' expectations of scores for online quizzes not being influenced by the use of specific electronic devices for learning activities. Even though several studies have shown that the use of computers, tablets, and mobile phones as a learning tool improves examination scores (Enriquez, 2010; Looi et al., 2015; Wilson et al., 2011), this study found that perceptions of the use of computers and tablets to do online quizzes do not significantly affect most of the specifications of student performance (hypotheses H5 to H8), probably because the advantages of computers and tablets for learning activities are offset by the disadvantages. However, the participants who did online quizzes on mobile phones obtained significantly lower examination scores than their peers (hypothesis H11). Although the use of mobile phones offers the flexibility to do online quizzes, as indicated by Liaw et al. (2010), these students' lower examination scores (compared to those of their peers) may indicate that their greater perception of the benefits of mobile phones for learning purposes nevertheless suggests being less academically focused than students who prefer distinct electronic devices, which is consistent with what was observed by Heflin et al. (2017). 


\section{Conclusions and implications}

Online quizzes as a learning resource allow students to actively participate in their learning processes by self-assessing their progress instantaneously on computers, tablets, and/or mobile phones. Thus, the effects of the perceptions of online quizzes and the use of computers, tablets, and/or mobile phones to do online quizzes on students' scores in these quizzes and in their examinations were examined. The findings reveal that positive perceptions of the use of computers, tablets, and/or mobiles phones positively affected perceptions of online quizzes (hypotheses H6, H9, and H12). However, perceptions of online quizzes on any electronic device had no influence on the SOQ construct (hypotheses H1, H4, H7, and H10). Only the perception of the use of mobile phones to do online quizzes negatively affected students' examination scores (hypothesis H11), while the perception of the use of computers and tablets for online quizzes did not affect them (hypotheses H5 and H8). Finally, and as previous research indicates, students' quiz performance positively influenced their examination scores (hypothesis H3). Therefore, scores for online quizzes were a factor that positively affected scores in paper-and-pencil exams. The model proposed by the present study had an acceptable goodness of fit. Therefore, the empirical model was appropriate for predicting and explaining the effect of the perceptions of online quizzes and of the use of computers, tablets, and/or mobile phones for doing them on students' quiz and examination scores.

\section{Research implications}

Previous literature investigated the influence of using online quizzes on students' learning process or studied the effects of using specific electronic devices (computers, tablets, or mobile phones) on performance compared to such traditional means as paper-and-pencil quizzes, but has not analysed the actual participants' perceptions of different electronic devices for doing online quizzes in the learning context, and their effect on examination scores. To fill this gap, this study developed and tested a partial least square structural equation model to test this. The results suggest meaningful and different effects of the scores for online quizzes and of the perceptions of the use of mobile phones to do online quizzes on examination scores. These findings are a reference for future studies related to the perception of electronic devices and student performance.

\section{Practical implications}

This study found that students' scores for online quizzes were the most important factor affecting their examination scores. Thus, higher (lower) scores for online quizzes can be used by lecturers and students to detect areas for improvement before taking other exams. However, the fact that perceptions of online quizzes affected students' examination scores but not their scores for online quizzes suggests that the advantages of online quizzes relate to knowledge assessment rather than the learning of course content. Therefore, instructors should explain the purpose of self-assessment to students, show them the benefits of using online quizzes to assess their knowledge, rather than using them to study the course content, and ensure that students are using this learning resource within the boundaries defined by instructors, while faculty administrators should provide the infrastructures and financial resources to implement effective online quizzes.

It was also found that perceptions of the use of mobile phones for online quizzes negatively affected students' examination scores. To overcome the difficulties for students using mobile phones for learning, reading, and accessing resources, instructors should integrate such learning activities as video or audio for mobile phones, which would help students to improve their examination scores, especially if they need to access learning resources anywhere and at any time.

\section{Research limitations and future work}

This study has several limitations. First, the sample consisted only of students enrolled at one university, which could limit its external validity. However, the Universitat Autònoma de Barcelona is a public university with a large number of students, which makes the results more generalisable. Second, the empirical setting did not control for differences in social, economic, or demographic characteristics (e.g., by distinguishing between working and non-working students, gender, or between students with or without a scholarship). However, previous studies focusing particularly on introductory accounting courses have found no gender-based differences in academic performance or the use of online quizzes (Martí Ballester 
\& Orgaz Guerrero, 2011). Future studies could examine how other social, economic, and demographic characteristics influence the association between electronic devices, online quizzes, and examination scores.

\section{Acknowledgements}

The authors are grateful to the participants at the 43rd EIBA Annual Conference of the European International Business Academy and at the 41st Annual Conference of the European Accounting Association for their valuable comments and suggestions. The authors are listed alphabetically and contributed equally to this manuscript.

\section{References}

Alvarez, C., Brown, C., \& Nussbaum, M. (2011). Comparative study of netbooks and tablet PCs for fostering face-to-face collaborative learning. Computers in Human Behavior, 27, 834-844. https://doi.org/10.1016/j.chb.2010.11.008

Bälter, O., Enström, E., \& Klingenberg, B. (2013). The effect of short formative diagnostic web quizzes with minimal feedback. Computers \& Education, 60(1), 234-242. https://doi.org/10.1016/j.compedu.2012.08.014

Barkatsas, A. T., Kasimatis, K., \& Gialamas, V. (2009). Learning secondary mathematics with technology: Exploring the complex interrelationship between students' attitudes, engagement, gender and achievement. Computers \& Education, 52(3), 562-570. https://doi.org/10.1016/j.compedu.2008.11.001

Bonham, S. W., Deardorff, D. L., \& Beichner, R. J. (2003). Comparison of student performance using web and paper-based homework in college-level physics. Journal of Research in Science Teaching, 40(10), 1050-1071. https://doi.org/10.1002/tea.10120

Boticki, I., Baksa, J., Seow, P., \& Looi, C. K. (2015). Usage of a mobile social learning platform with virtual badges in a primary school. Computers \& Education, 86, 120-136. https://doi.org/10.1016/j.compedu.2015.02.015

Brothen, T., \& Wambach, C. (2001). Effective student use of computerized quizzes. Computers in Teaching, 28(4), 292-294. https://doi.org/10.1207/S15328023TOP2804_10

Buchanan, T. (2000). The efficacy of a world-wide web mediated formative assessment. Journal of Computed Assisted Learning, 16, 193-200. https://doi.org/10.1046/j.1365-2729.2000.00132.x

Chang, C. C., Yan, C. F., \& Tseng, J. S. (2012). Perceived convenience in an extended technology acceptance model: Mobile technology and English learning for college students. Australasian Journal of Educational Technology, 28(5), 809-826. https://doi.org/10.14742/ajet.818

Chen, J. L. (2011). The effects of education compatibility and technological expectancy on e-learning acceptance. Computers \& Education, 57(2), 1501-1511. https://doi.org/10.1016/j.compedu.2011.02.009

Chen, Q., \& Yan, Z. (2016). Does multitasking with mobile phones affect learning? A review. Computers in Human Behavior, 54, 34-42. https://doi.org/10.1016/j.chb.2015.07.047

de-Marcos, L., Hilera, J. R., Barchino, R., Jiménez, L., Martínez, J. J., Gutiérrez, J. A., Gutiérrez, J. M., \& Otón, S. (2010). An experiment for improving students' performance in secondary and tertiary education by means of m-learning auto-assessment. Computers \& Education, 55, 1069-1079. https://doi.org/10.1016/j.compedu.2010.05.003

Di Meo, F., \& Martí Ballester, C. P. (2019). Survey. Retrieved from https://www.researchgate.net/publication/333312086_Survey

Duffy, T. M., \& Jonassen, D. H. (1992). Constructivism and the technology of instruction: A conversation. Hillsdale, NJ: Erlbaum.

Elliott-Dorans, L. R. (2018). To ban or not to ban? The effect of permissive versus restrictive laptop policies on student outcomes and teaching evaluations. Computers \& Education, 126, 183-200. https://doi.org/10.1016/j.compedu.2018.07.008

Engeström, Y. (1999). Activity theory as individual and social transformation. In Y. Engeström, R. Miettinen, \& R. L. Punamaki (Eds.), Perspectives on activity theory (pp. 19-38). Cambridge, UK: Cambridge University Press.

Enriquez, A.G. (2010). Enhancing student performance using tablet computers. College Teaching, 58, 77-84. https://doi.org/10.1080/87567550903263859 
Ferrer, F., Belvís, E., \& Pàmies, J. (2011). Tablet PCs, academic results and educational inequalities. Computers \& Education 56, 280-288. https://doi.org/10.1016/j.compedu.2010.07.018

Fornell, C., \& Larcker, D. F. (1981). Evaluating structural equation models with unobservable variables and measurement error. Journal of Marketing Research 18(1), 39-50. https://doi.org/10.2307/3151312

Garcia-Cabot, A., de-Marcos, L., \& Garcia-Lopez, E. (2015). An empirical study on m-learning adaptation: Learning performance and learnings contexts. Computers \& Education, 82, 450-459. https://doi.org/10.1016/j.compedu.2014.12.007

Gretes, J. A., \& Green, M. (2000). Improving undergraduate learning with computer-assisted assessment. Journal of Research on Computing in Education, 33(1), 46-54. https://doi.org/10.1080/08886504.2000.10782299

Hair, J. F., Ringle, C. M., \& Sarstedt, M. (2011). PLS-SEM: Indeed, a silver bullet. Journal of Marketing Theory and Practice, 19(2), 139-152. https://doi.org/10.2753/MTP1069-6679190202

Heflin, H., Shewmaker, J., \& Nguyen, J. (2017). Impact of mobile technology on student attitudes, engagement, and learning. Computers \& Education, 107, 91-99. https://doi.org/10.1016/j.compedu.2017.01.006

Henseler, J. (2014, November). Common factor models, composite models, and formative measurement: Their nature, application, and testing. Lecture conducted as part of the International Business and Strategic Management doctorate program, Universidad de Sevilla, Seville, Spain.

Huang, Y. M., \& Lin, P. H. (2017). Evaluating students' learning achievement and flow experience with tablet PCs based on AR and tangible technology in u-learning. Library High Tech, 35(4), 602-314. https://doi.org/10.1108/LHT-01-2017-0023

Hwang, G. J., \& Chang, H. F. (2011). A formative assessment-based mobile learning approach to improving the learning attitudes and achievements of students. Computers \& Education, 56, 10231031. https://doi.org/10.1016/j.compedu.2010.12.002

Hwang, G. J., Yang, T. C., Tsai, C. C., \& Yang, S. J. H (2009). A context aware ubiquitous learning environment for conducting science experiments. Computers \& Education, 53(2), 402-413. https://doi.org/10.1016/j.compedu.2009.02.016

Ifenthaler, D., \& Schweinbenz, V. (2016). Students' acceptance of tablet PCs in the classroom. Journal of Research on Technology in Education, 48(4), 306-321. https://doi.org/10.1080/15391523.2016.1215172

Junco, R., \& Cotten, S. R. (2012). No A 4 U: The relationship between multitasking and academic performance. Computers \& Education, 59, 505-514. https://doi.org/10.1016/j.compedu.2011.12.023

Kates, A. W., Wu, H., Coryn, C. L. S. (2018). The effects of mobile phone use on academic performance: A meta-analysis. Computers \& Education, 127, 107-112. https://doi.org/10.1016/j.compedu.2018.08.012

Kim, T. H., \& Jin, S. H. (2015). Development of auditory design guidelines for improving learning on mobile phones. Computers \& Education, 91, 60-72. https://doi.org/10.1016/j.compedu.2015.09.011

Li, S. C., Pow, J. W. C., Wong, E. M. L., \& Fung, A. C. W. (2010). Empowering student learning through tablet PCs: a case study. Education and Information Technologies, 15(3), 171-180. https://doi.org/10.1007/s10639-009-9103-2

Liaw, S. S., Hatala, M., \& Huang, H. M. (2010). Investigating acceptance toward mobile learning to assist individual knowledge management: Based on activity theory approach. Computers \& Education, 54(2), 446-454. https://doi.org/10.1016/j.compedu.2009.08.029

Looi, C. K., Sun, D., \& Xie, W. (2015). Exploring students' progression in an inquiry science curriculum enabled by mobile learning. IEEE Transactions on Learning Technologies, 8(1), 43-54. https://doi.org/10.1109/TLT.2014.2376968

Lowther, D. L., Ross, S. M., \& Morrison, G. M. (2003). When each one has one: The influence on teaching strategies and student achievement of using laptops in the classroom. Educational Technology Research and Development, 51(3), 23-44. https://doi.org/10.1007/BF02504551

MacDonald, C. J., \& Gabriel, M. A. (1998). Toward a partnership model for web-based learning. The Internet and Higher Education, 1(3), 203-216. https://doi.org/10.1016/S1096-7516(99)80167-5

Marriott, P., \& Lau, A. (2008). The use of on-line summative assessment in an undergraduate financial accounting course. Journal of Accounting Education, 26, 73-90. https://doi.org/10.1016/j.jaccedu.2008.02.001

Martí Ballester, C. P., \& Orgaz Guerrero, N. (2011). El cuestionario como herramienta de autoevaluación en el proceso de aprendizaje de la asignatura Contabilidad Financiera y Analítica [Interactive questionnaires as self-assessment tool for accounting subjects]. Educade: Revista de Educación en 
Contabilidad, Finanzas y Administración de Empresas, 2, 51-66. Retrieved from http://www.educade.es/images/pdf/numeros/n2/03-marti.pdf

Martí Ballester, C. P., \& Orgaz Guerrero, N. (2014). Análisis del uso de cuestionario en contabilidad financiera [Using questionnaires in financial accounting]. Educación XX1, 17(1), 271-290. https://doi.org/10.5944/educxx1.17.1.10714

Martí-Ballester, C. P., \& Simon, A. (2017). Union is strength: The integration of ISO 9001 and ISO 14001 contributes to improve the firms' financial performance. Management Decision, 55(1), 81-102. https://doi.org/10.1108/MD-09-2015-0414

Miller, T. (2009). Formative computer-based assessment in higher education: The effectiveness of feedback in supporting student learning. Assessment \& Evaluation in Higher Education, 34(2), 181192. https://doi.org/10.1080/02602930801956075

Nicol, D. (2007). E-assessment by design: Using multiple-choice tests to good effect. Journal of Further and Higher Education, 31(1), 53-64. https://doi.org/10.1080/03098770601167922

Nikou, S.A., \& Economides, A.A. (2016). The impact of paper-based, computer-based and mobile-based self-assessment on students' science motivation and achievement. Computers in Human Behavior, 55 , 1241-1248. https://doi.org/10.1016/j.chb.2015.09.025

Nunnally, J. C. (1978). Psychometric theory (2nd ed.). New York, NY: McGraw-Hill.

Nunnally, J. C., \& Bernstein, I. H. (1994). Psychometric theory (3rd ed.). New York, NY: McGraw-Hill.

Ozok, A., Benson, D., Chakraborty, J., \& Norcio, A.F. (2008). A comparative study between tablet and laptop PCs: User satisfaction and preferences. International Journal of Human-Computer Interaction, 24(3), 329-352. https://doi.org/10.1080/10447310801920524

Pruet, P., Ang, C.S., \& Farzin, D. (2016). Understanding tablet computer among primary school students in underdeveloped areas: Students' technology experience learning styles and attitudes. Computers in Human Behavior, 55. 1131-1144. https://doi.org/10.1080/15391523.2016.1215172

Ricketts, C., \& Wilks, S.J. (2002). Improving student performance through computer-based assessment: insights from recent research. Assessment \& Evaluation in Higher Education, 27(5), 475-479. https://doi.org/10.1080/0260293022000009348

Ringle, C. M., Wende, S., \& Becker, J. M. (2014-2019). SmartPLS 3.0. Boenningstedt, Germany: SmartPLS GmbH. Retrieved from http://www.smartpls.com/

Romero, C., Ventura, S., \& de Bra, P. (2009). Using mobile and web-based computerized tests to evaluate university students. Computer Applications in Engineering Education, 17(4), 435-447. https://doi.org/10.1002/cae.20242

Sánchez-Franco, M. J., Peral-Peral, B., \& Villarejo-Ramos, Á. F. (2014). Users' intrinsic and extrinsic drivers to use a web-based educational environment. Computers \& Education, 74, 81-97. https://doi.org/10.1016/j.compedu.2014.02.001

Scibora, L. M., Mead, T., \& Larson, C. (2018). The influence of iPads on course performance and student perceptions of learning in human anatomy. Journal of Teaching and Learning with Technology, 7(1), 108-124. https://doi.org/10.14434//jotlt.v7n1.23973

Segall, N., Doolen, T.L., \& Porter, J.D. (2005). A usability comparison of PDA-based quizzes and paperand-pencil quizzes. Computers \& Education, 45, 417-432. https://doi.org/10.1016/j.compedu.2004.05.004

Sellin, N., and Keeves, J.P. (1994). Path analysis with latent variables. In T. Husen \& T. N. Postlethwaite (Eds.), International encyclopedia of education (pp. 4352-4359). London, UK: Elsevier.

Sharples, M., Taylor, J., \& Vavoula, G. (2005). Towards a theory of mobile learning. In H. van der Merwe \& T. Brown (Eds.), Mobile technology: The future of learning in your hands. mLearn 2005 Book of Abstracts (p. 58). Cape Town, South Africa: mLearn. Retrieved from http://www.mlearn.org.za/CD/papers/Sharples-\%20Theory\%20of\%20Mobile.pdf

Shih, J. L., Chu, H. C., Hwang, G. J., \& Kinshuk. (2011). An investigation of attitudes of students and teachers about participating in a context-aware ubiquitous learning activity. British Journal of Educational Technology, 42(3), 373-394. https://doi.org/10.1111/j.1467-8535.2009.01020.x

Song, Y. (2014). "Bring Your Own Device (BYOD)" for seamless science inquiry in a primary school. Computers \& Education, 74, 50-60. https://doi.org/10.1016/j.compedu.2014.01.005

Summers, J. J, Waigandt, A., \& Whittaker, T. A. (2005). A comparison of student achievement and satisfaction in an online versus a traditional face-to-face statistics class. Innovative Higher Education 29(3), 233-250. https://doi.org/10.1007/s10755-005-1938-x

Tang, T. L. P., \& Austin, M. J. (2009). Students' perceptions of teaching technologies, application of technologies, and academic performance. Computers \& Education, 53(4), 1241-1255.

https://doi.org/10.1016/j.compedu.2009.06.007 
Terzis, V., \& Economides, A. A. (2011). The acceptance and use of computer based assessment. Computers \& Education, 56(4), 1032-1044. https://doi.org/10.1016/j.compedu.2010.11.017

Wardley, L. J., \& Mang, C. F. (2016). Student observations: Introducing iPads into university classrooms. Education and Information Technologies, 21(6), 1715-1732. https://doi.org/10.1007/s10639-0159414-4

William, D., \& Black, P. (1996). Meanings and consequences: A basis for distinguishing formative and summative functions of assessment? British Educational Research Journal, 22, 537-548. https://doi.org/10.1080/0141192960220502

Wilson, K., Boyd, C., Chen, L., \& Jamal, S. (2011). Improving student performance in a first-year geography course: Examining the importance of computer-assisted formative assessment. Computers \& Education, 57, 1493-1500. https://doi.org/10.1016/j.compedu.2011.02.011

Corresponding author: Fabrizio Di Meo, fabrizio.dimeo@uah.es

Copyright: Articles published in the Australasian Journal of Educational Technology (AJET) are available under Creative Commons Attribution Non-Commercial No Derivatives Licence (CC BY-NC-ND 4.0). Authors retain copyright in their work and grant AJET right of first publication under CC BY-NC-ND 4.0.

Please cite as: Di Meo, F., \& Martí-Ballester, C.-P. (2020). Effects of the perceptions of online quizzes and electronic devices on student performance. Australasian Journal of Educational Technology, 36(1), 111-125. https://doi.org/10.14742/ajet.4888 